\title{
' $\mathrm{R}$ I0r.'
}

By Prof. R. V. Southweld, F.R.S.

$\mathbf{A}^{\mathrm{T}}$ dawn on Saturday, Oct. 12, 'R 101' was taken from her shed at Cardington and brought, without difficulty or delay, to her anchorage at the mooring mast. The week-end was devoted to tests of her engines and ballasting equipment; but on Monday, Oct. 14, with fifty-two people on board, she left the mast and cruised for about $5 \frac{1}{2}$ hours over the home counties and London. Such tests and measurements as could be made during the flight indicated that the airship fulfils in every way her designers' expectations; with three engines running at cruising power, an average air speed of about 58 miles an hour was maintained.

On Friday, Oct. 18, a second flight was made. Air speeds well in excess of 60 m.p.h. were attained, and again the manœuvre of 'coming to the mast' presented no difficulty, although it took longer on this occasion, because the airship was found, on nearing ground level, to have an unexpectedly high 'lift' (or buoyancy). Between her first and second flights ' $\mathrm{R} 101$ ' had been subjected at the mast to winds of considerable strength and variability, accompanied by sudden changes of temperature: her behaviour gave no grounds for anxiety, and seems to justify (so far as it goes) the preference which the Aeronautical Research Committee has expressed for this scheme of mooring in comparison with others that have been proposed. As I write, ' R 101' lies again in her shed, having left the mast to make room for the Burney airship ' $\mathrm{R} 100$ ', due to arrive from Howden.

So for the first time since 1921, when failure of a girder resulted in the total loss of ' $\mathrm{R} 38$ ', an airship designed and constructed in Great Britain has been seen in flight. Naturally ' R 101 ' has aroused great interest, and the merit of her initial achievements has been admitted even by journals which, a month ago, were fulminating at once against the mistakes of her design and the impenetrable secrecy by which those designs had been surrounded. Optimism is once more in the ascendant, and sanguine predictions are being made regarding ' $R$ 101', ' $\mathrm{R} 100$ ', and their successors.

The danger of such optimism is that, being a plant of very rapid growth, it is liable to wilt in the chill of even a temporary set-back; therefore I cannot feel that true service is rendered to the cause of airships by suggestions that all their difficulties have been overcome. The Times (which almost alone among our daily papers has maintained a rational and consistent attitude towards ' this airship business ') put the matter clearly in a sentence of its leader of Oct. 15: "After all, $\mathrm{R} 101$ is admittedly experimental". Four years ago $I$ stressed the same aspect in an evening discourse to the British Association 1 : "I wish that the public could be induced to see this airship construction as a great adventure: the goal, ability to fly to India, in comfort and without change, in the space of 100 hours; the problem, to design

2 Brit. Assoc. Reprint No. 19. and construct a ship of vast capacity, with little help from past experience, by *sheer hard thinking and hard work." Then I was pleading for (what has not been accorded) suspense of judgment on the new designs until their problems should have been worked out. Now, when ' $R$ 101's ' designers are receiving the plaudits they so richly deserve, it is still the aspect of adventure that I should wish to stress ; but now for the reason that, counting too confidently on success, we may slacken in determination to surmount the difficulties that remain.

In 1925 , only main outlines had been decided in the design of ' $\mathrm{R} 101$ '. I shall try to state briefly, first in what respects I consider that the anticipations of those days have been realised, and afterwards, in what respects the available evidence seems to me to be either negative or incomplete. I need scarcely add that my views carry no weight of authority, and are based on no exclusive information; my contact with ' $\mathrm{R} 101$ ' has been solely in relation to technical problems of stress calculation, except in so far as I have been permitted by the kindness of the staff at Cardington to watch the progress of their work.

In my discourse to the British Association I ventured to defend the policy of the Air Ministry which, after four years' stagnation in airship construction, was then embarking on the adventure of ships just twice as large as any that had been built previously. I had been speaking of the "dimensional handicap"--equally ruthless in its pressure on birds and aeroplanes-which " makes our problem harder when we go to greater size", and I had said: "I do not say that we have yet reached a limit in respect of size of aeroplanes: new materials, new principles of construction and, above all, new types of engine may relieve the pressure of the laws which I have been discussing. All that I am concerned to show is that this pressure will be merely " postponed " ". But, as I went on to show, the airship, which relies for its "lift" upon its buoyancy, "experiences a relatively insignificant dimensional handicap in the stresses which it has to sustain. . . By doubling every dimension, we obtain an airship which will carry eight times as much load, and can withstand winds of the same strength as before." Its parallel in Nature (according to my argument) is to be found, not in the bird, but in the whale.

I urged, further, that a certain advantage can in fact be expected to accrue from increased size. "Suppose that we took an existing airship (R 33, say) and decreased every dimension by two. According to dimensional theory it could still fly and it would have adequate strength, but in reality its construction would have become impossibly flimsy. . . . Conversely, by increasing the size, and employing material of stouter gauge, we lessen the importance of corrosion, .... we render possible methods of construction which were not practicable 
before, .... and we lessen the chance of accidental damage." I think it may be said, speaking generally, that these contentions have been sustained. ' $R 101$ ' is robust; the scantlings of her steel girders are such that full advantage could be taken of experience gained in the construction of metal spars for aeroplanes; and simple joints could be provided by which the ship was assembled rapidly, as though from the elements of a vast 'Meccano' set. What this means in simplicity of construction can be realised from Fig. 1, in which two typical joints are compared,one from ' R 101', the other of 'Zeppelin' construction, and both fulfilling almost exactly the
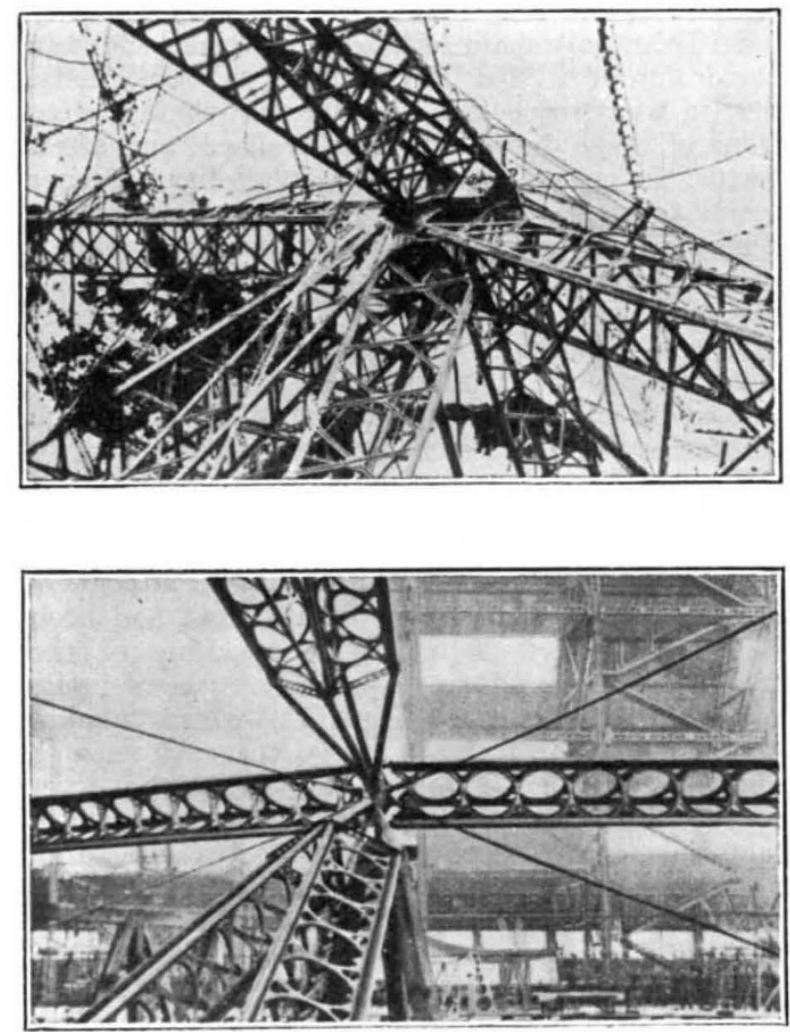

FIg. 1.--Typical joints, above, of 'Zeppelin' construction, below, from ' $\mathrm{R}$ 101' Royal Air Force official : Crown copyright reserved.

same purpose. The 'Zeppelin' joint involves a large amount of hand riveting in situ: in ' $\mathrm{R} 101$ ', finished members are assembled by a mere insertion of bolts and nuts.

In one respect, admittedly, the advance to greater size was an advance into the region of the unknown. It is a commonplace of aerodynamical theory that model tests, in the present state of knowledge, afford no certain indication of the characteristics to be expected in the full-scale. Therefore at the National Physical Laboratory, when we based on such tests our recommendations in regard to shape of hull, we were careful to make only guarded estimates of resistance (that is, of speed), and to emphasise that the amount of 'balance' suggested for the control surfaces might prove on trial to be either insufficient or excessive.
We believed that our estimate of speed would prove to be conservative, and that the hull would be satisfactory in respect both of stability and control; but we hesitated to base quantitative figures on models which had perforce to be made on a scale of about $1 / 20$ inch to 1 foot, and Cardington accordingly decided to provide 'Servo-motor' auxiliaries for working the controls, in case these should prove "heavier' than was expected.

According to the Times report of Oct. 16, 1500 h.p. sufficed in the first trial to give the airship a speed of 58 m.p.h. It may be deduced with practical certainty (since the power required will vary as the cube of the speed) that with her five engines giving 700 b.h.p. each (the figure contemplated originally) ' $\mathrm{R} 101$ ' could have developed a speed of 77 m.p.h.,-which is slightly in excess of her estimated speed. Recourse to the Servo-motor gear was not found necessary (if this holds good at full speed the gear may be removed, and then about $\frac{1}{2}$ ton will be added to the useful ' lift '), and the stability of the ship was reported to be entirely satisfactory. Thus the trials, so far as they go, give no support to those critics who upbraided the temerity of our decision to recommend a shape considerably less elongated than those of past German airships. I have never been able to understand the reasoning which convinced them (quite independently of any question of 'scale-effect') that the new shapes must prove specially difficult to control; on the structural side it should be obvious that the hull (which is a girder, serving to transmit the concentrated loads of the passengers and engines) must benefit by being made relatively short and deep. Perhaps they failed to visualise the meaning of a 'fineness-ratio' of $5 \cdot 5$ : as Fig. 2 indicates, the shape of ' $\mathrm{R} \mathrm{101}$ ' is short in comparison with earlier ships, but it is not appropriately described as 'plump'.

Space does not permit a description of the many ingenious devices which Col. Richmond, the chief designer, and his small band of assistants have incorporated in their design. The interested reader may be referred to the Journal of the Royal Aeronautical Society, August 1929, for a full description, and I must be content here to express the unqualified admiration I have learned to feel for their work-an admiration which will persist even if (as I do not expect) ' $R$ 101' is ultimately pronounced to be a failure. I turn now to the other side of the picture-the problems which still await solution.

The Achilles' heel of ' $R$ 101', so far as it is possible to judge at present, is her power plant. No one is to blame for this circumstance, but it cannot be denied, and it is very serious. Designed to carry five engines of 700 b.h.p., ' $\mathrm{R}$ 101 ' can at present count only on four, and these will not develop continuously more than about 600 b.h.p. each. $^{2}$ So her designed power has been reduced by more than 30 per cent, and the 77 m.p.h. which she should attain at full power is replaced by a figure slightly under 68 : against a head wind of 60 m.p.h.

"See letter from the Editor of Aircraft Engineering in the Times of (T. R. Cave-Browne-Cave) in the Journal R. Ae. Soc., March 1929. 
she can make good only 8 ground miles per hour, instead of 17. Moreover, the engines are heavy. They weigh 7 Ib. per h.p. 'dry' - a figure about twice as high as that which Mr. Chorlton, their designer, considers to be possible now, and was believed to be possible when the design of ' $\mathrm{R} 101$ ' was started. Five tons will be added to the useful load if and when these hopes are realised. ${ }^{3}$

The 'troubles' which have led to this result were enumerated by Wing-Commander Cave-BrowneCave in his lecture to the Royal Aeronautical Society: torsional resonance of the crankshafts (a fault which is difficult to remedy at a late stage in design) has necessitated increased weight and delayed the fitting of "variable pitch airscrews" ; the aluminium crankcases gave trouble (as origin-
In the original project, ' $\mathrm{R} 101$ ' was planned to run on heavy fuel oil, using engines which were to be developed from a marine type weighing about $100 \mathrm{lb}$. per b.h.p. The high flash-point of the fuel would eliminate the danger of fire occurring in tropical temperatures; greater distances could be flown on a given weight of fuel; and the cost of fuel would be largely reduced. In ' $\mathrm{R}-100$ ' the same objectives were to be attained by the use of engines burning a mixture of paraffin and hydrogen, - thus utilising gas which otherwise would be valved, and so wasted. The latter engines have not materialised, and ' $\mathrm{R} 100$ ' is, for the present, to burn petrol after all : ' $R$ 101', as we have seen, has attained her objective, but at a serious cost in loss of speed.

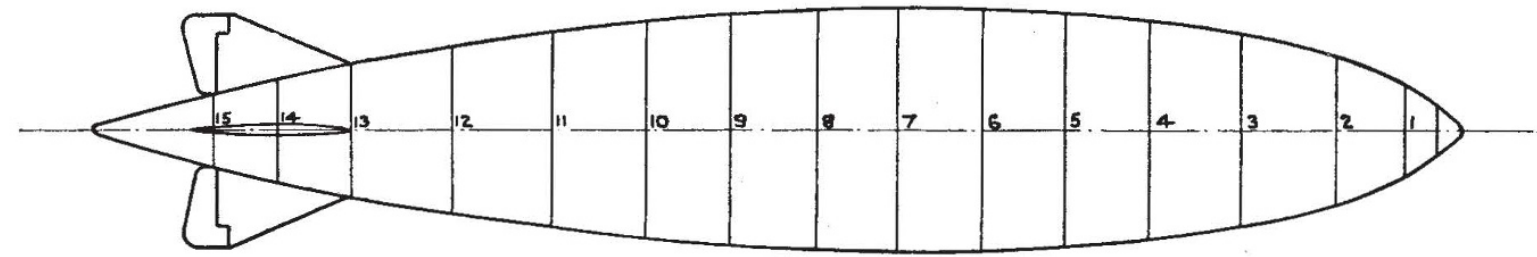

OUTLINE OF HULL. R.IOI.

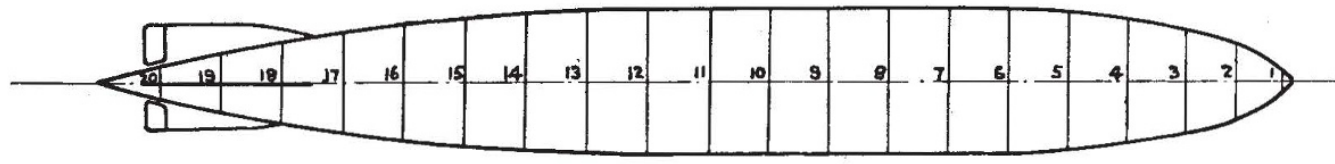

OUTLINE OF HULL. R.33.

DRAWN TO SAME SCALE.

FIG. 2.-Outlines of hull of ' $R$ 101' and ' $R$ 33'. Royal Air Force ofticial: Crown copyright reserved.

ally designed) and have been replaced by steel. Wing-Commander Cave remarked that " none of the major troubles has been due to the engine working with heavy oil". In a strictly technical sense this statement is true, but in the wider aspect it may be misleading; for the decision to use heavy oil meant that special engines had to be designed $a b$ initio, whereas, had petrol been the intended fuel, engines of tried reliability could have been incorporated.

Let me say at once that I consider the Air Ministry's decision, based on its determination to aim at 'safety first', to have been in every way right and wise. Airships in Great Britain have still to win public confidence, and a disaster sustained by either of the new ships would probably result again (as in 1921) in a total cessation of construction. The difficulty that has arisen is solely a matter of time : a new engine, working on a relatively novel principle, takes longer to perfect than an airship hull.

3 See Mr. Choriton's letter in the Times of Oct. 19.
The consequence is that these two airships, originally intended to be exactly comparable and so to test the relative efficiency of 'official' and independent commercial design, are not directly comparable to all. ' $\mathrm{R} 100$ ', with her six RollsRoyce engines, can count on 4200 b.h.p., ${ }^{4}$ but she cannot (according to the standards originally imposed) safely be flown in the tropics. ' $R$ 101' is safe to fly as regards fire risk, but her depleted speed introduces an element of danger of another kind, and in really strong winds her captain will have anxieties for which her designer is in no way responsible. From the scientific point of view one must regret that she, too, has not been equipped to run on petrol, as a temporary expedient, until such time as her heavy-oil engines have been brought more closely into accord with their intended performance. A year spent in temperate climates-on flights planned with a view to the accurate measurement of speed, controllability, hull stresses and the like-would yield knowledge 
of incalculable value regarding the merits of the new designs, and would enable the flights to Egypt and to India to be planned with greater confidence. Both airships are experimental, and the experiment ought not to be hurried at any cost in added risk.

As matters stand, comparison is still possible, but it must be made with care : relative figures, if given without full explanation, may be entirely misleading. Thus, in regard to speed, the measured performances of the two ships must be 'corrected' (according to the cube law which expresses the power-speed relation) in order that their hull resistances may be compared on a basis of equal power; the fact that they carry widely different power plants is (speaking scientifically) an irrelevant circumstance which this procedure will serve to eliminate. Similar remarks apply to the question of useful lift, or "pay load'; the heavier engines carried by ' $\mathrm{R} 10 \mathrm{l}$ ' must not be allowed to detract from our estimate of her structural design, nor from this point of view is she entitled to credit for the fact that 1 ton of heavy oil represents a wider radius of action than 1 ton of petrol. Either ship might have been fitted with either power plant; therefore the hulls must be compared for efficiency, as engineering structures, on a basis of the total weight which they can carry, for the same quantity of hydrogen, in passengers, crew, furniture, engines, and fuel combined.

Finally, the comparison must be made on a basis of figures ascertained in actual flight, not on estimates. How easily the latter may be in error is indicated by the remark that at least a ton of dust had settled on ' $\mathrm{R} 101$ ' during her time of waiting in the shed. ${ }^{5}$ Useful lift can be estimated only as a (relatively) small difference between two large quantities: when the hull is air-borne it can be measured with certainty. Estimates, it is safe to say, have been the curse of airships: so hard to check, when airship flights are as infrequent as solar eclipses; so easily modified to suit the thesis of the moment, whether sanguine or condemnatory.

The enthusiast, whose millenium is always five years ahead, can seldom resist the temptation to detract from actual achievement, in order that the advantages of his new project may be displayed in stronger light ; he forgets that it is only on achievement that the outside world, with sound instinct, will base its expectations and its support of airships. To those who have the progress of airships most at heart, it is a relief to pass from a period of words and 'estimates' to a period in which the new ships must stand their trial. Very soon now we shall know with certainty the relative merits of ' $\mathrm{R} 100$ ' and ' $\mathrm{R} 101$ ', and how they compare with the airships of other countries; then, but not until then, can future projects be based on sure foundations.

s Times of Oct. 14.

\section{The British Association in South and East Africa. ${ }^{1}$}

\section{By Sir Richard Gregory.}

W HEN the Prince of Wales was president of the British Association at the Oxford meeting in 1926, he made particular reference in his address to the value of meetings of the Association overseas in creating interest in science and co-ordinating the work and results of scientific investigators throughout the Empire. "Nothing but good", he remarked, " can follow from personal contact between scientific workers in different parts of the Empire. Nothing but good can follow from their researches if they add, as gradually they must add, to the wider knowledge of the Empire not only among the workers themselves, but ultimately among the whole body of informed Imperial citizenship ; not only in the overseas territories, but also at home."

As one of the main functions of the British Association is to bring home to the public the significance and value of science to human life, nothing now would seem more natural than to extend these activities occasionally to fields of the Empire overseas and not to confine meetings to the British Isles. More than half a century elapsed, however, from the foundation of the Association before the first overseas meeting was held at Montreal in 1884. Since then meetings have been held twice in South Africa, once in Australia, and in Canada again in 1897 and 1909, and every meet-

1 From an address on "Science and the Empire" given on Dec. 3 at a meeting of the Royal Empire Society in co-operation with the British Association, following upon the recent meeting of the Association in South Africa. ing has had very decided influence in stimulating scientific work in the country visited as well as engaging the interest of the visitors in the solution of new problems. There is no longer any doubt as to the importance of acquiring first-hand knowledge of our overseas territories, or need to emphasise the good that results from personal contact between workers in various parts of the Empire. Co-operation and co-ordination are essential to avoid waste of effort and secure rationalisation in science, and the British Association is greatly assisting progress towards this end by its overseas meetings.

The world has to look to tropical agriculture for a large part of its food supply and raw materials in the future, and to ensure that this will be forthcoming it is essential that the fullest scientific knowledge should be available and used to protect crops from the pests which continually assail them in tropical countries. In Africa in particular, the facts to be faced and the problems to be solved are set forth most convincingly in the Report of the Parliamentary Commission of Inquiry to East Africa in 1924 and in Mr. Ormsby-Gore's report on the four British West African territories in 1926. One of the most gratifying features of the former report was the recognition of the economic value of scientific guidance to such countries. Mr. Ormsby-Gore was chairman of the East African Commission, and he had the advantage of co-

No. 3137 , VoL. 124] 